\title{
Bibliometric Analysis on Global Research Trends of Airborne Microorganisms in Recent Ten Years (2011-2020)
}

\author{
Yonghao Jia ${ }^{1}$, Yihan Chen ${ }^{1}$, Ping Yan ${ }^{3}$, Qianli Huang ${ }^{1,2 *}$ \\ ${ }^{1}$ School of Resources and Environmental Engineering, Hefei University of Technology, Anhui, \\ Hefei 230009, China \\ ${ }^{2}$ School of Food and Biological Engineering, Hefei University of Technology, Anhui, Hefei \\ 230009, China \\ ${ }^{3}$ Zhongnan University of Economics and Law, Wuhan, Hubei 430073, China
}

\section{ABSTRACT}

In recent years, exposure to bioaerosols - airborne particles of biological origin - has become a significant public health concern. Hence, this study aims to provide a bibliometric analysis of global trends in research on airborne microorganisms in the last ten years (2011-2020).

Using the Web of Science (WoS) Core Collection database, a total of 1087 articles published during this period were selected for analysis. Firstly, we identified 11 co-citation clusters: potential pan microbiome, bioaerosol science, beneficial microbe, urban area, fungal microbiota, wastewater treatment plant, airborne microbial aerosol, modern practice, composting facilitiesa review, airborne microbial biodiversity, and acidic electrolyzed water. Based on the co-occurrence between keywords in this literature, we concluded that particle-attached microorganisms, community structures of urban airborne microbes, and biological aerosols have inspired the hotspots in research during recent years, which suggests that bioaerosols are currently a popular topic in the field of air microbiology, with bacteria being the most frequently studied airborne microorganisms. We also discovered that interest in coronavirus disease 2019 (COVID-19) has continually risen during the past eight months, with the number of relevant articles exceeding 19,880 , of which 106 have been frequently cited. Analyzing 500 recent publications on this topic, we found a high co-occurrence of COVID-19, pandemic, and coronavirus as well as of anxiety, depression, and stress.

The greatest number of articles on airborne microorganisms in the last decade have been contributed by the USA, followed by China and France. Moreover, according to this metric, the leading institutions are Colorado State University and Peking University, and the top three journals are Applied and Environmental Microbiology, Atmospheric Environment, and Science of the Total Environment. The annual publication volume for this subject shows an increasing trend, indicating that interest in airborne microorganisms continues to grow.

Our bibliometric analysis reveals the recent research hotspots and topic trends in air

Publisher:

Taiwan Association for Aerosol Research

ISSN: $1680-8584$ print

ISSN: 2071-1409 online

Copyright: The Author(s). This is an open access article distributed under the terms of the Creative Commons Attribution License (CC BY 4.0), which permits unrestricted use, distribution, and reproduction in any medium, provided the original author and source are cited.

Keywords: Airborne microorganism, Air quality, Web of Science (WoS), Human health, COVID-19

\section{INTRODUCTION}

In recent years, with the frequent occurrence of extreme weather events such as disaster, air quality has attracted more and more public attention. The atmosphere is essential to maintain life on Earth. Microorganisms are ubiquitous in the air, including not only bacteria and fungi, but also viruses that may be harmful to human health. There are various forms of microorganisms in the air, which can float in the air as a single cell or attach to atmospheric particles (Yoo et al., 2017). Previous studies have shown that there are tens of thousands of microorganisms in every 
cubic meter of air (Tignat-Perrier et al., 2019). Microorganisms in the air, especially in indoor air, have potential effects on human health (Brodie et al., 2007; Yoo et al., 2017). Many bacteria and viruses (in particular, coronavirus disease 2019 [COVID-19] attracted attention) can rely on air as a medium to cause epidemic diseases (Fan et al., 2019; Parat et al., 1999). For example, COVID19 , which broke out in Wuhan in early 2020, can enter the air through droplets and cause infection through human respiration (Stadnytskyi et al., 2020). COVID-19 can be spread through droplets, saliva and airborne particles (Adjorlolo and Egbenya, 2020). Due to the rapid spread of COVID-19 and its great harm to human body, people pay more attention to air microorganism once again. A paper entitled "Surviving Sepsis Campaign: Guidelines on the management of critically ill ads with coronavirus disease 2019 (COVID-19)." In the case of rapid spread of COVID19 , how to achieve effective prevention and control, infection control means, and according to the resources and feasibility of control suggestions (Alhazzani et al., 2020). Many articles have reported the effects of COVID-19 on human health, such as liver and intestine (Juliao-Baños, 2020; León-Gómez, 2020). At the same time, many researchers focus on air quality changes during the epidemic period and the effects of regional climatic condition on the spread of COVID19 at global scale (Berman and Ebisu, 2020; Iqbal et al., 2020). Because of the characteristics of microorganisms staying in the air for a long time, the scope of infection is wider and the possibility of infection is increased. Especially in recent years, $\mathrm{PM}_{2.5}$ and $\mathrm{PM}_{10}$ are focused on, and the attached microorganisms are considered to cause the transmission of allergy, respiratory diseases and infection (Cao et al., 2014). It is reported that bacteria and dust in the air of pig farms cause respiratory diseases, irritating eyes and nose, and accompanied with allergic symptoms (Crook et al., 1991; Lin and Ma, 2010; Zhao et al., 2014). The study reported the composition of microorganisms in the air near the sewage treatment plant, the source of bacterial transmission, and assessed the risk to human health. It showed that the types and concentrations of air microorganisms are significantly different in each stage of water treatment, and may cause employees and residents to produce chronic respiratory diseases (Yang et al., 2019).

Additionally, the types and quantity of microorganisms vary with seasons, places, weather and urban economic level (Fang et al., 2020; Rao et al., 2020; Tignat-Perrier et al., 2020). Airborne microorganisms not only exist in the air and stay in the air for a long time, but also migrate with the airflow and other meteorological conditions. The chemical composition of $\mathrm{PM}_{10}$ in southeastern Italy was reported (Romano et al., 2020). Through 165 sequencing to determine the microbial community structure, it was found that the seasonal variation of atmospheric particulate matter was one of the reasons for the seasonal variation of atmospheric bacterial community. Similarly, the association between microbial composition, chemical composition, and other environmental factors in the Turkish air was studied (Després et al., 2012; Lang-Yona et al., 2020). This paper studied the bacteria in the air of the central Mediterranean region, including the main distribution of bacteria, bacterial abundance and biodiversity from winter to spring. The results showed that bacterial abundance increases in convective weather (Romano et al., 2019). Moreover, hospitals and health centers are a more dangerous and complex environment, and microorganisms with greater potential impact on human health may exist in the nearby air. Some researchers took air samples from the wards of pulmonary tuberculosis patients to observe whether there was Mycobacterium tuberculosis (MTB). The results were positive, indicating that there was Mycobacterium tuberculosis in the air (Wan et al., 2004). Also, previous studies have shown that forest air samples contain Phytophthora infestans, which can cause ulcers in humans (Jung et al., 2018). The results hold that there are not only viruses and bacteria in the air with potential health risks, but also that both the mobility of air and air pressure make it more difficult to prevent these diseases. Due to the complexity and diversity of air microorganisms and their potential impact on air quality and human health (Brągoszewska et al., 2019), the topic of airborne microorganisms is very important and deserves more attention.

There are many journals and magazines related to a specific field, and thence it is very difficult to have a comprehensive understanding. Thus, bibliometrics came into being. Through bibliometric tools, we can analyze the research hotspots and trends of a certain field. It will help researchers to better capture the authoritative articles in this field, grasp the overall direction of the field more quickly, and explore hints and clues (Fahimnia et al., 2015).

Although many papers about airborne microorganisms have been reported, few attempts 
have been carried on this field from the perspective of bibliometrics. This study analyzed the articles about airborne microbes from WoS database in recent ten years.

\section{METHODS}

\subsection{Data Source}

Our data are retrieved from the Web of Science Core Collection (from 1985 to 2020) (www.webofknowledge.com/WOS), which includes the world's leading scholarly journals, books, and proceedings in the sciences, social sciences, and arts and humanities. WoS includes the Science Citation Index Expanded (SCIE), SSC, the Arts \& Humanities Citation Index (A\&HCI), Ei Compendex, MEDLINE and other core journals. Although the search results of different core databases are different, WoS has become the preferred database because of its many advantages. For example, a) the citations of all publications can be searched and obtained, b) organizations related to the author of the article can be searched, and c) the citation report can be created according to the search results. Moreover, most bibliometric tools support data formats exported from WoS.

\subsection{Search Strategy}

It is necessary to select search keywords and check whether the search results are consistent with the expected topics. Here, through searching with airborne microorganism in the subject terms, a total of 1607 related articles are screened out. Subsequently, the year was selected as the screening criteria, and 1087 articles were selected from the last ten years (2011-2020). To avoid problems caused by the update of articles in the database, our search is fixed on July 13 , 2020. Since WoS can export up to 500 records at a time, all the search results are exported in three times.

\subsection{Data Analysis}

In the present study, many bibliometric indicators, such as the cooperation network between different institutions and the co-occurrence network of keywords, were utilized to evaluate the topic from different aspects. Several tools/software were adopted to perform bibliometric analyses. For instance, CiteSpace (version 5.3.R4.8.31.2018; http://cluster.cis.drexel.edu/ cchen /citespace/) was used for citation and co-citation analysis (Synnestvedt et al., 2005). Having fantastic visualization styles and being capable of loading and exporting information from many sources, VOSviewer (version 1.6.15; https://www.vosviewer.com/) was employed to construct and visualize bibliometric networks. Moreover, to show the importance of the articles in the database, two other concepts including average citations per item and $h$-index were introduced. Average citations per item refers to the average number of articles cited in all search results. And $h$-index means that $h$ papers/journals have been cited at least $h$ times.

\section{RESULTS AND DISCUSSION}

\subsection{Co-citation Analysis}

Co-citation reflects the relationship between two cited documents. In other words, when two documents appear in the same article's references at the same time, the two articles form a cocitation relationship. In this study, we analyzed 1087 articles on airborne microorganisms from 2011-2020. Using clustering, log likelihood ratio (LLR) algorithm and term frequency-inverse document frequency (TFIDF) weighting technology, the network was divided into 11 co-citation groups. The results were shown in Fig. 1. These clusters were marked by their citer index entries. From large to small, these clusters are: beneficial microbe, potential pan microbiome, bioaerosol science, urban area, fungal microbiota, wastewater treatment plant, airborne microbial aerosol, modern practice, composting facilities - a review, airborne microbial biodiversity, and acidic electrolyzed water. Among them, the most cited article was about Beijing smog incident, namely "Inhalable Microorganisms in Beijing's $\mathrm{PM}_{2.5}$ and $\mathrm{PM}_{10}$ Pollutants during a Severe Smog Event" (Cao et al., 2014). Obviously, this research on the particle-attached microorganism has attracted 


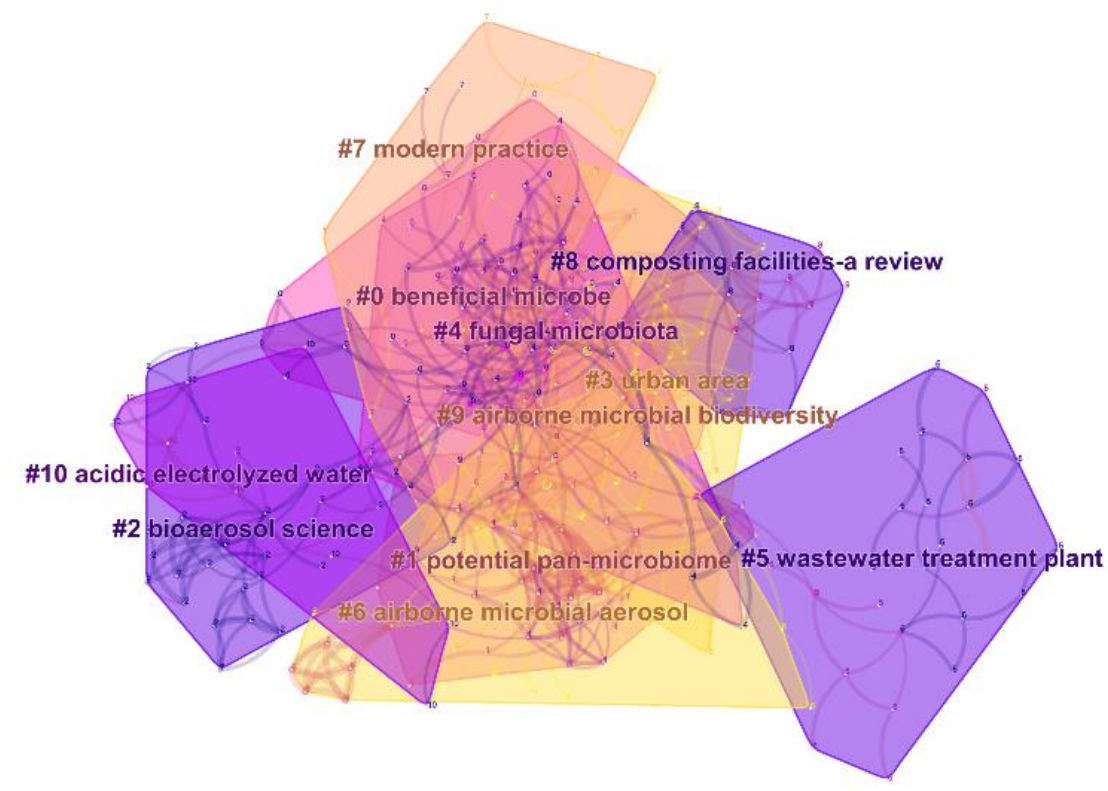

Fig. 1. Co-citation of literature. The top 11 clusters are clustered by CiteSpace software. The selection criteria are: top 50 per slice, $L R F=2, L B Y=8, e=2.0$. These clusters are labeled by index terms from their cities, and each cluster is represented by different colors.

widespread attention. At the beginning of 2020, a large-scale outbreak of the new coronavirus disease 2019 caused by SARS-CoV-2 virus has attracted worldwide attention since its discovery. The virus can attach to aerosols and atmospheric particles, and spread rapidly from person to person through respiratory tract (del Rio and Malani, 2020). The topic of the second most cited article is about the difference between land use types and the community structure of air microbes in the air near the surface (Bowers et al., 2011). The subject of the third most cited document is about atmospheric aerosol particles, in which the main components of biological aerosols (including viruses, bacteria, fungi, and algae) were examined in detail (Després et al., 2012). So, in recent years, the research hotspots in air microorganisms mainly focus on particleattached microorganisms, the community structure of urban air microbes, and biological aerosols.

\subsection{Co-occurrence Network of Keyword}

Generally, keywords highlight the core content of a paper, through which we can understand the theme and search engines can find relevant papers easily. By considering the co-occurrence of keywords in several papers, the relationship between the subjects represented by the literature collection can be disclosed (Lozano et al., 2019). Here, to facilitate analysis, the parameters were set as follows: The counting method is "Full counting," the standardized method adopts "Association strength," and the minimum number of occurrences of a keyword is 20. Among 4839 keywords in the 1087 articles, 87 keywords meet the screening threshold, which were further divided into 5 clusters in the network through calculating the co-occurrence link strength between a group of keywords and other groups of keywords. The co-occurrence network of keywords was depicted in Fig. 2. Among them, the keywords microorganism, bioaerosol, and bacterium are the top three keywords, and the frequency of co-occurrence is 387,249 and 234 respectively. It indicated that bioaerosol is a hotspot and current trend in the field of air microbiology, and the most studied species of airborne microorganisms are bacteria. It should be noted that the minimum COVID-19 can be $40 \mathrm{~nm}$ and the average size is $100 \mathrm{~nm}$; it reaches the level of nanoaerosol (Leung and Sun, 2020).

This indicates that COVID-19 is a component of bioaerosol. In addition, air quality, indoor air quality, health, prevalency, infection also appear in the first few keywords, and viruses can also be adsorbed on particles and aerosols, affecting air quality and human health. Compared with bacteria, fungi and aerosols, the frequency of virus occurrence is relatively less, which indicates that the virus has not attracted widespread attention in the past period of time. The bacteria, 
(a)

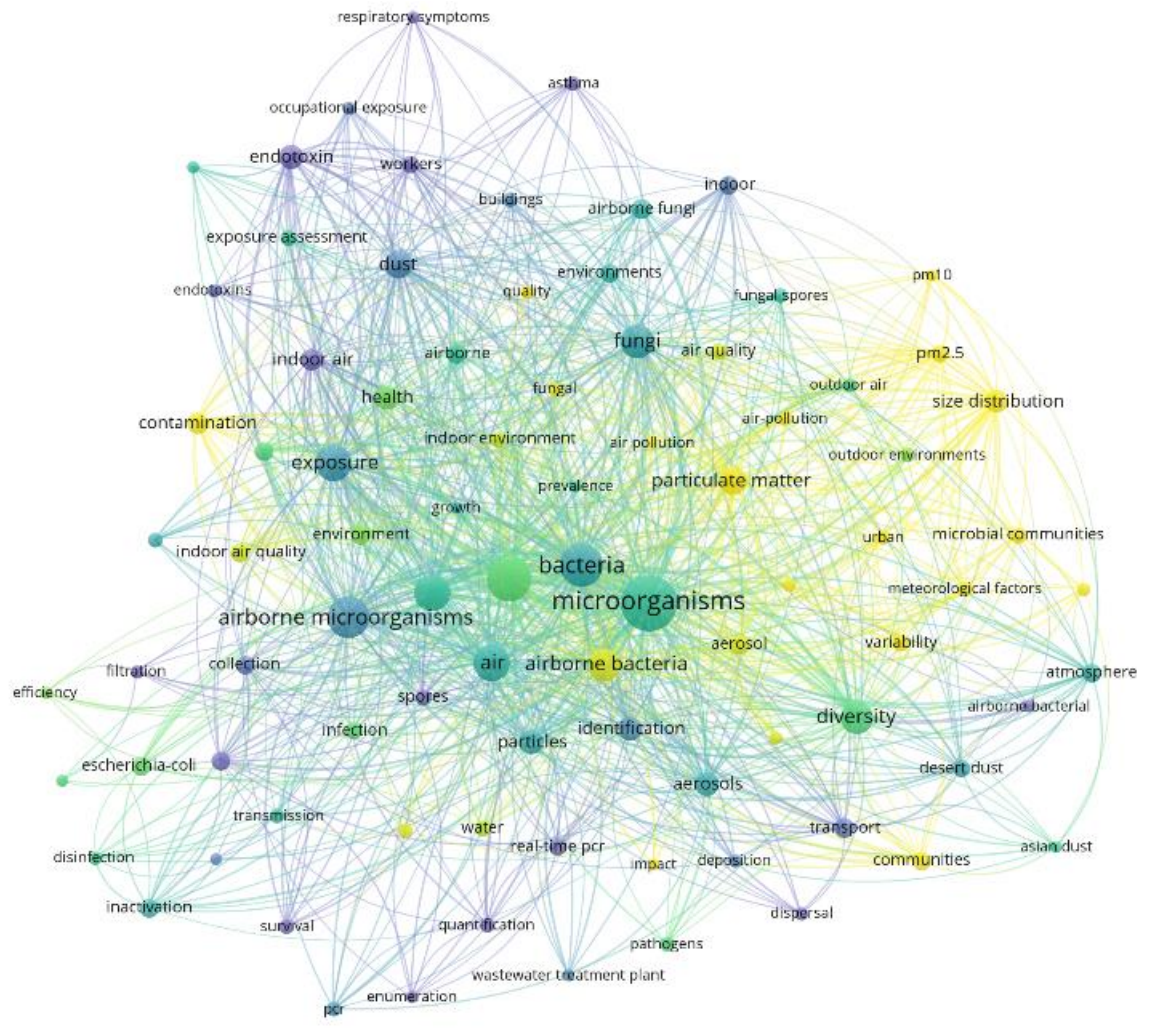

(b)

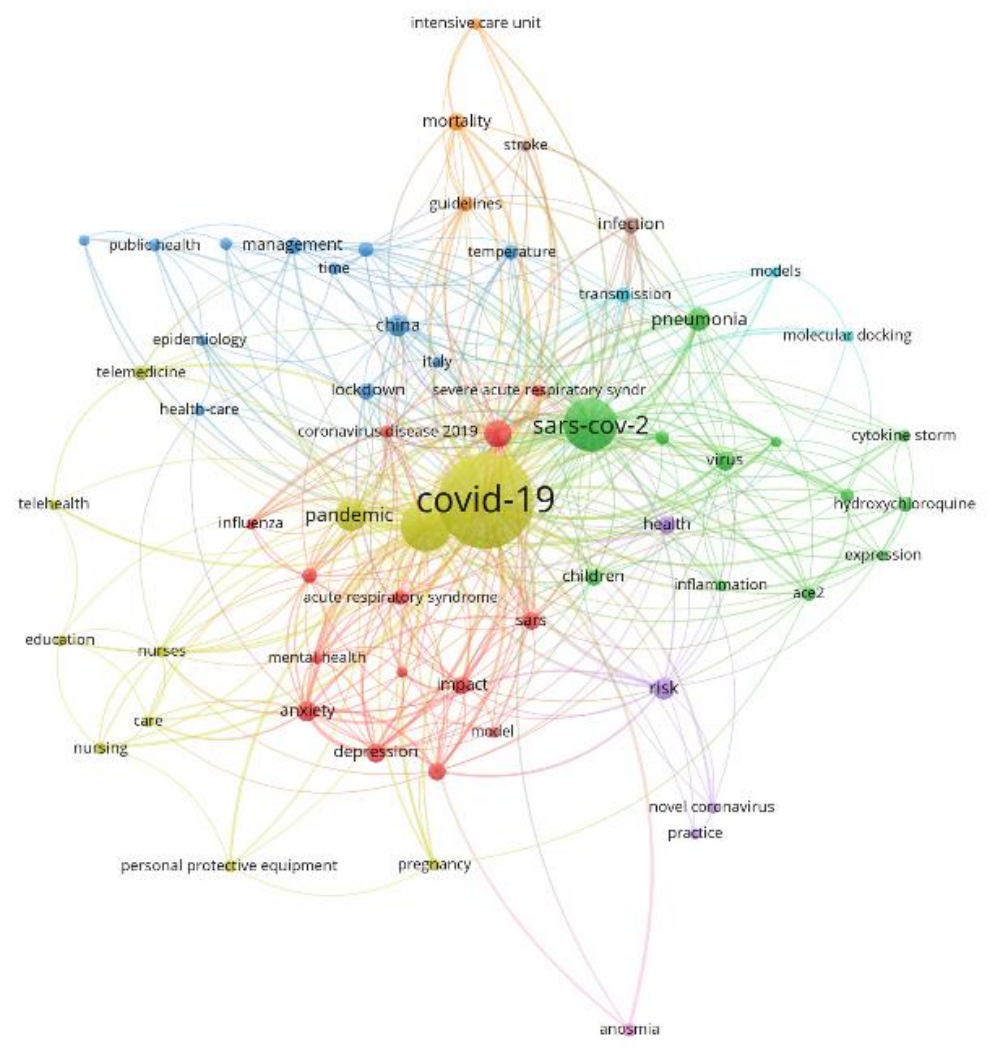

Fig. 2. Co-occurrence network of keywords. (a) 5 clusters are obtained by clustering keywords by using VOSviewer software. The timeline is displayed in the lower right corner. Each circle represents a keyword, and the size of the circle represents the co-occurrence frequency of the keywords obtained by clustering. The color of the line indicates the year, and the shorter the line, the higher the frequency of the two keywords connected. (b) The keyword co-occurrence graph of 500 newly published articles is divided into 9 clusters and 62 items. 
fungi and viruses in $\mathrm{PM}_{2.5}$ and $\mathrm{PM}_{10}$ were identified. 48 bacteria, 2 fungi and 4 viruses were found. Among these microorganisms, several can cause allergic and respiratory symptoms, such as Streptococcus pneumoniae, Aspergillus fumigatus, and human adenovirus C (Cao et al., 2014). The results are consistent with the previous studies (Froehlich-Nowoisky et al., 2016). Perhaps, because the pathogenic bacteria in the aerosol can cause many human diseases (such as allergies and respiratory tract especially for specific occupations) (Kim et al., 2018), the topic of bioaerosol has attracted such high attention. Interestingly, the dominant time scale for publishing articles on this type of topic mainly ranged from 2015 to May 2016. This might result from that there were more air pollution incidents around the world during this period. It has aroused people's extensive concern.

The co-occurrence analysis of COVID-19 was carried out with 500 articles published recently. The results are shown in Fig. 2(b). Besides COVID-19, pandemic and coronavirus, the co-occurrence frequency of anxiety, depression and stress was high. This shows that in addition to the epidemic itself, researchers also pay attention to the psychological health impact of COVID-19 (Duan et al., 2020; Van Rheenen et al., 2020), especially the mental health problems of teenagers (Duan et al., 2020; Gribble et al., 2020).

\subsection{Analysis on Major Countries and Institutions}

Each country and institution may have different research focus. To identify the similarities and differences among the countries and institutions in the field of air microbes, the countries and institutions in the literature are clustered according to the number of citations and displayed by thermal map (Figs. 3(a) and 3(b)). A total of 81 countries have participated in the investigation of airborne microorganisms. When the minimum number of documents of a country is set as 5 , 42 countries meet the criteria. With 212 articles and 5031 citations, the USA is the dominant country in this field with 195 papers published and 2536 citations; China ranked second. And France took the third position with 77 papers and 1179 citations. Notably, the number of published articles and citations of the top three cited countries far exceeds that of other countries. This indicates that the USA, China and France are more concerned about airborne microbes and maybe in the leading position in this issue. Moreover, in the dataset of this study, a total of 1392 institutions participated in the research field. According to the number of citations, the first name is Colorado State University, with 14 papers and 857 citations. The second is Peking University, from which the number of published articles is 26 and the number of citations is 709; the third is Seoul National University, with 18 articles and 289 citations. Besides, the number of papers published by Colorado State University is small, but the citation frequency is high. It implies that the quality of articles in Colorado State University is relatively high, or the points of the articles are more interesting. According to the comprehensive ranking of the total connection strength between each institution and other institutions, Chinese Academy of Sciences, University of the Chinese Academy of Sciences, and Peking University occupied the top three leading institutions. This demonstrated that these institutions have carried out extensive scientific cooperation.

\subsection{Analysis on Cooperation Network of Different Countries and Institutions}

To further examine the cooperation among countries and institutions, the cooperation network was constructed according to the data in the literature collection and shown in Figs. 4(a) and $4(b)$. The results suggested that China and the USA are more active, not only in the number of citations or cooperative relations but also in the forefront of research. The focus of research mainly includes South Africa, natural source, breeding farm, case-control study, and silvermodified $\mathrm{TiO}_{2}$. As shown in Fig. 4(b), the top three active institutions are Chinese Academy of Sciences, Peking University and University of the Chinese Academy of Sciences, and the focus of these institutions harbors precipitation, bioaerosols, airborne microorganisms, Asian dust, and metadata. Moreover, there is relatively more cooperation among countries from 2011 to 2016, and mainly focus on precipitation, biological aerosols, airborne microorganisms, Asian dust, metadata, and microbial communities. The above results indicated that on the topic related to airborne microbes, the cooperative relationship between the state and the institution was closer during 2011-2016. But on the whole, the cooperation relationship across countries and institutions is deficient. Given that environmental problems are not the responsibility of a single 
(a)

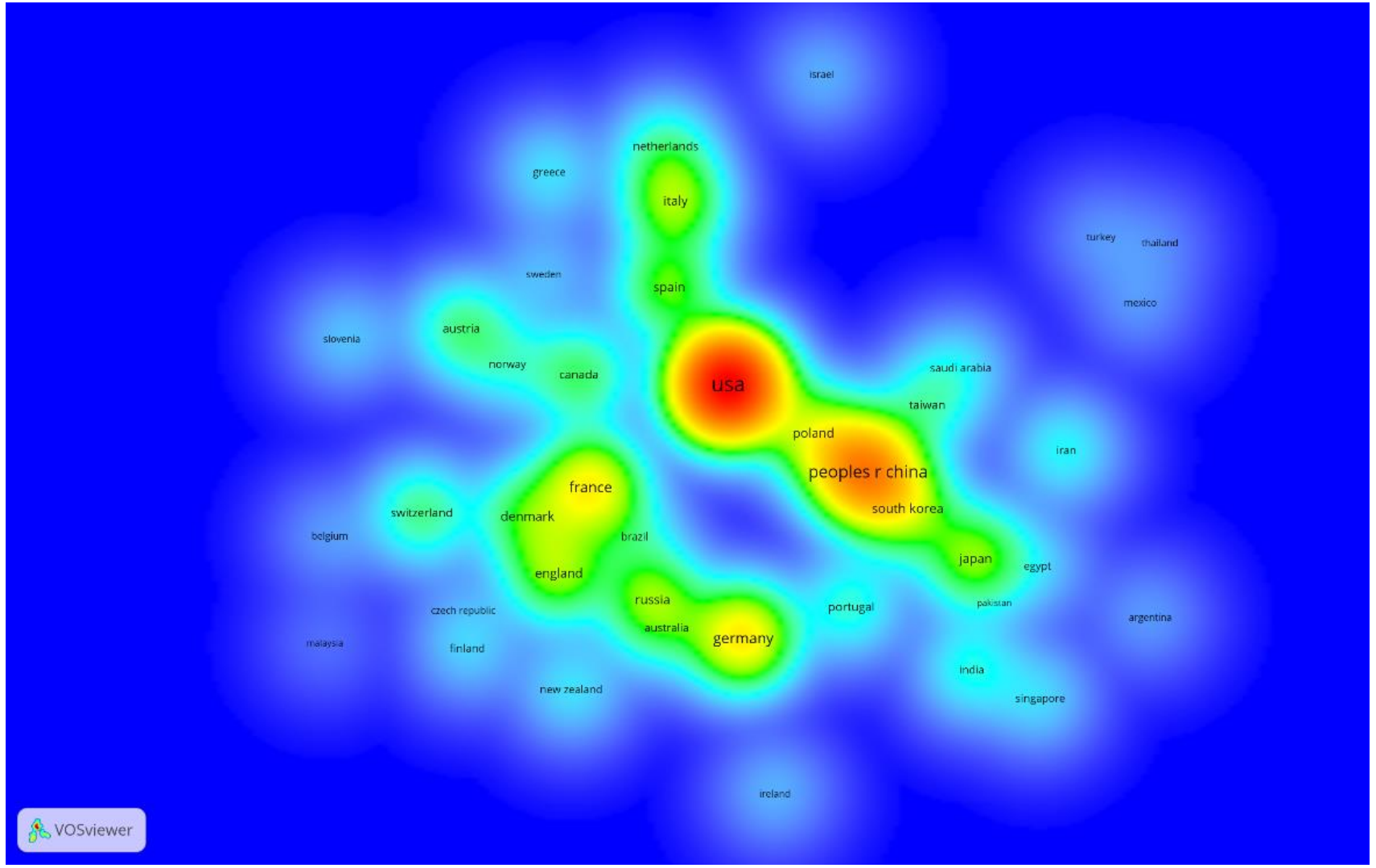

(b)

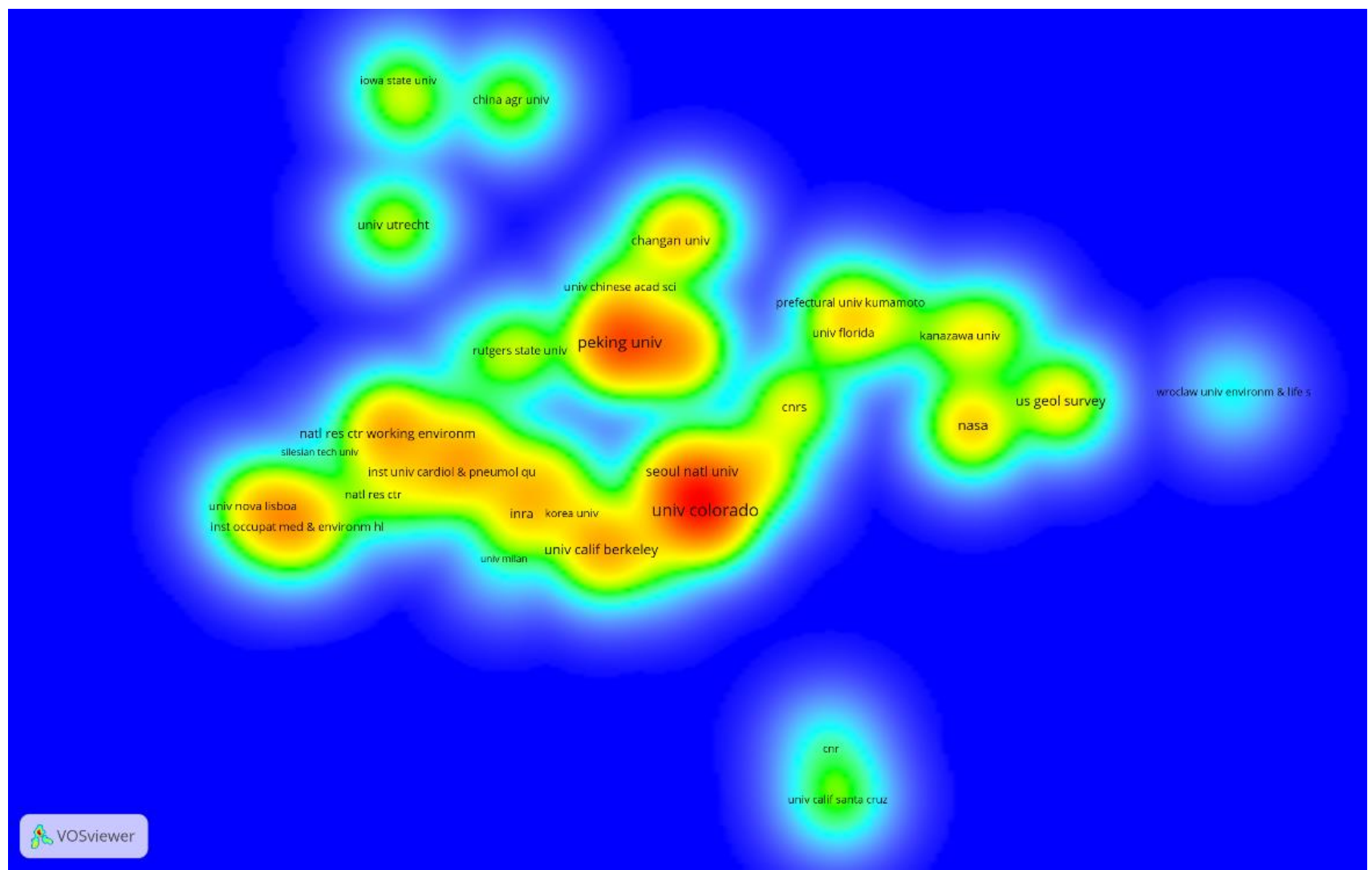

Fig. 3. Heat maps of leading (a) countries and (b) institutions. By using the VOSviewer software, the leading countries and institutions in the field of air microorganisms are obtained by sorting the institutions and countries according to the cited amount. As displayed by thermography, the number of citations is depicted as color from blue to red. And the redder the color is, the more dominant it is in this field. 
(a)

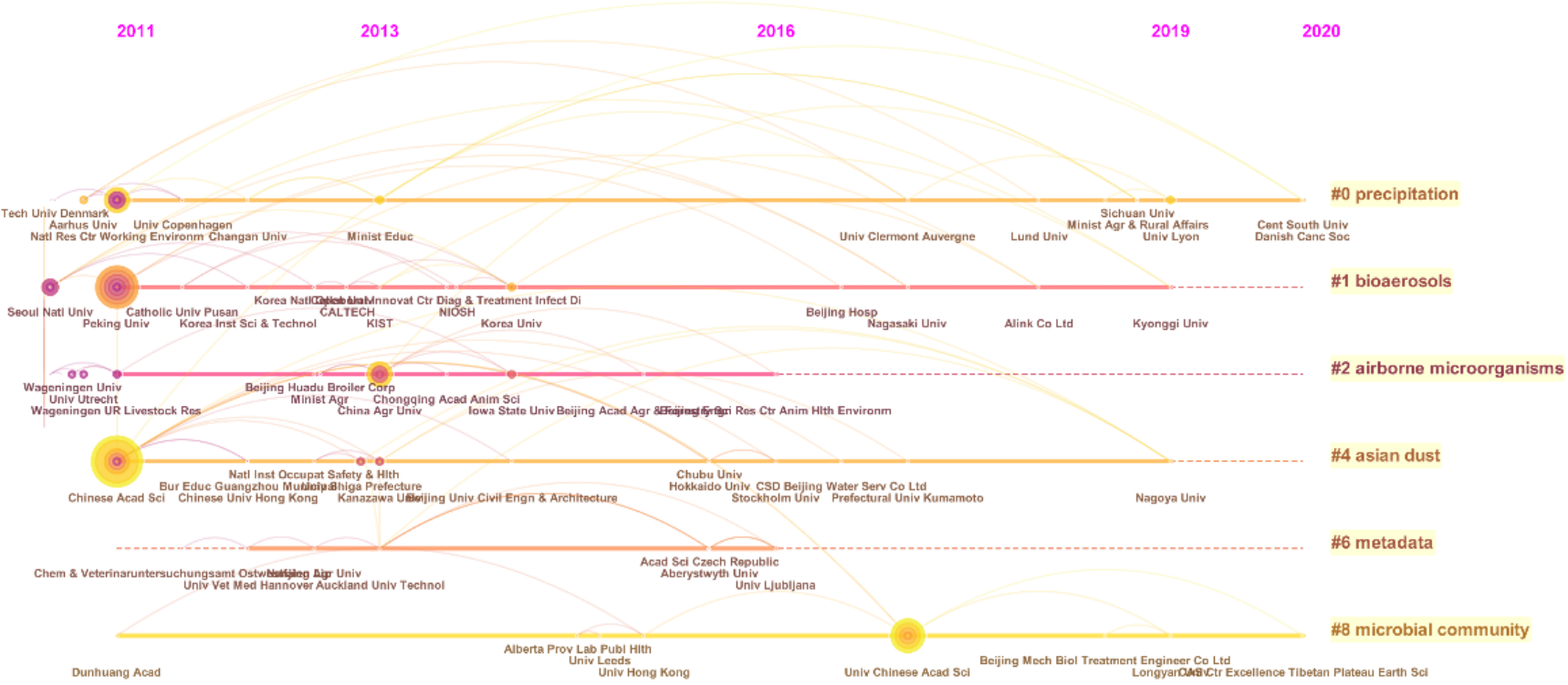

(b)

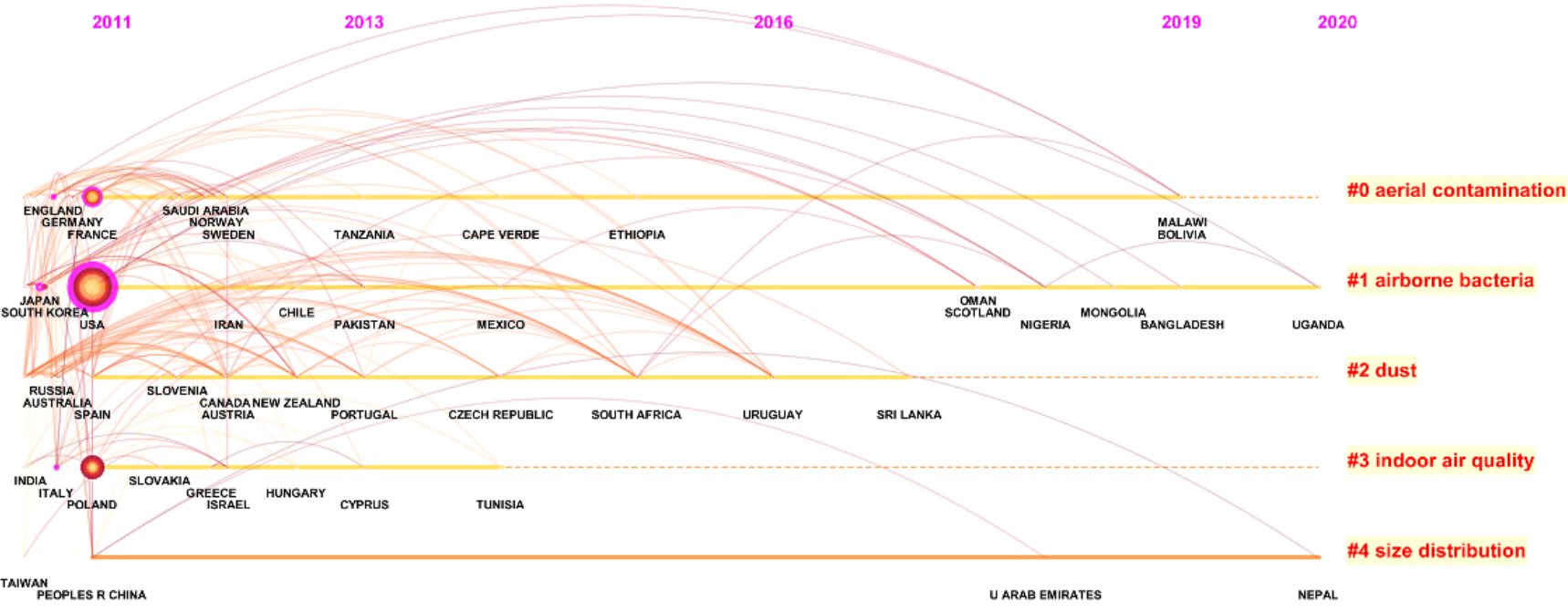

Fig. 4. Network of cooperation among different institutions and countries. The collaboration networks were constructed according to the authors' (a) countries and (b) institutions. The right side represents the cluster label. The larger the node circle, the more countries or institutions in the cluster.

country, this provides us a hint that environmental research and improvement require more collaboration and joint efforts.

\subsection{Analysis on Source Journals}

To investigate the activity of journals in the field, source journals of the literature were analyzed. When the minimum number of citations is set to 90 , among the 9035 sources, 94 sources meet the threshold and were divided into 4 clusters. To make the graph more intuitive, the max lines was set to 500. The network of source journals is shown in Fig. 5. Based on the analysis of the source journals, Applied and Environmental Microbiology (Appl. Environ. Microbiol.) ranked first with 2423 citations, followed by Atmospheric Environment (Atmos. Environ.) and Science of the Total Environment (Sci. Total Environ.). The results suggested that the quality of articles in these three journals is relatively high in the field of air microbiology. Furthermore, Table 1 shows the top seven journals ranked according to the number of citations. $h$-Index means that $h$ articles in the journal have been cited for at least $h$ times. It is a relatively popular index to evaluate journals. It is more reliable than the average value because it is not affected by the highest value. Obviously, these journals are very important for this research field. 


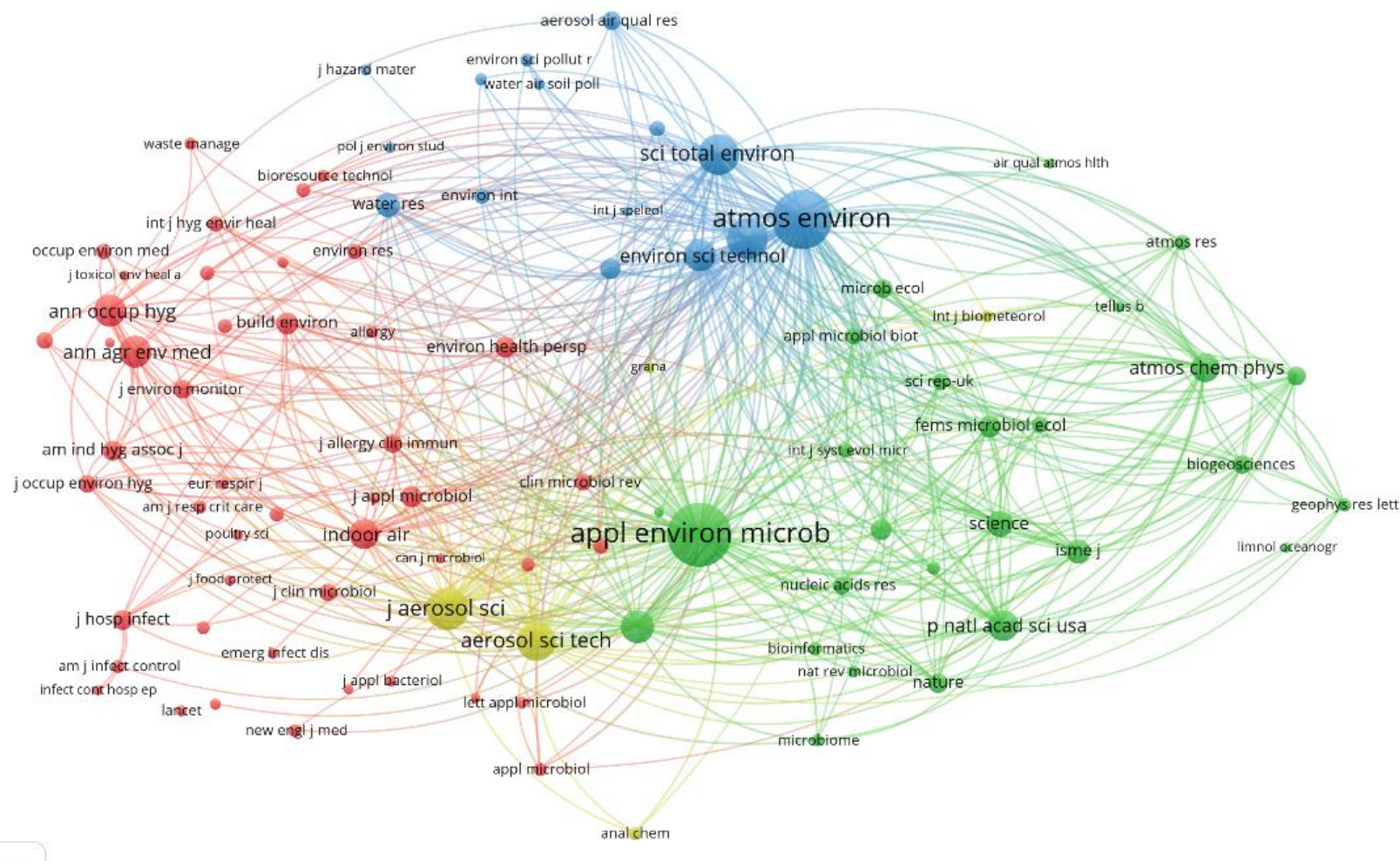

\& vosviewer

Fig. 5. Co-citation network. The node circles represent different journals. Different colors denote different clusters, and the distance between lines indicates the co-citation intensity of journal pairs.

Table 1. Information of the seven most frequently cited journals.

\begin{tabular}{llll}
\hline Rank & Journal & h-index & Citations \\
\hline 1 & Appl. Environ. Microbiol. & 293 & 2423 \\
2 & Atmos. Environ. & 211 & 2145 \\
3 & Sci. Total Environ. & 205 & 1121 \\
4 & J. Aerosol Sci. & 98 & 1137 \\
5 & Aerobiologia & 43 & 1083 \\
6 & Aerosol Sci. Technol. & 95 & 1010 \\
7 & PLOS ONE & 268 & 760 \\
\hline
\end{tabular}

Especially for the researchers who are new to airborne microorganisms, these journals are undoubtedly more important references. In particular, Aerosol and Air Quality Research (AAQR), which focuses on aerosols and air quality, has a citations of 268 and total connection strength of 11,065 about air microorganisms, which is in the upper middle position. The results show that $A A Q R$ has a leading level in the field of air microorganism, which guides the research direction of scholars.

\section{CONCLUSIONS}

\subsection{Discussion of Results}

1087 articles on airborne microorganisms published between 2011 and 2020 were selected from the Web of Science Core Collection database and analyzed for their keywords, authors, affiliated institutions, and countries of origin in order to identify hotspots and trends in research during the last decade. First, the co-citation in these publications reveals 11 clusters, viz., potential pan microbiome, bioaerosol science, beneficial microbe, urban area, fungal microbiota, 


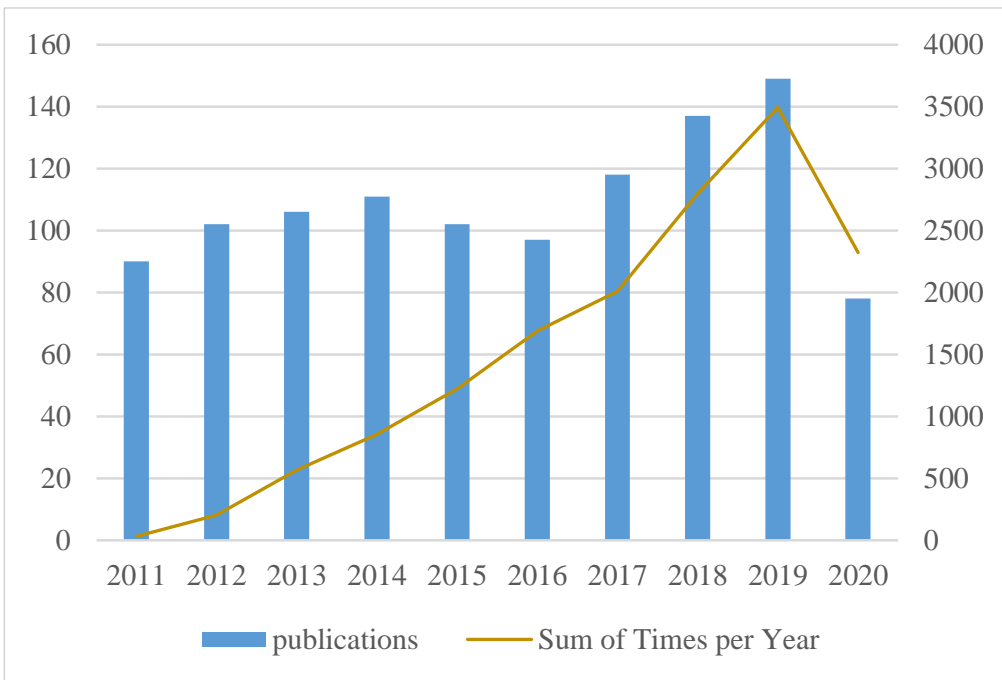

Fig. 6. The total number of papers published and the corresponding number of citations in the last ten years. The annual number of articles published and the corresponding number of citations in 1087 articles are summarized. The left label is the annual number of publications, and the right label is the annual citation frequency.

wastewater treatment plant, airborne microbial aerosol, modern practice, composting facilitiesa review, airborne microbial biodiversity, and acidic electrolyzed water. Second, analysis of keyword co-occurrence network in this field suggests that the recent hotspots in research have been related to microorganism, bioaerosols, and bacterium, with the 500 newest articles also indicating strong concern over psychological issues in children due to COVID-19. To successfully cope with this virus, we must not only treat the physical symptoms and control the infection rate but also address mental health and the effects of economic depression and severe, albeit brief, lifestyle changes.

Applying the number of citations as a metric, the USA, followed by China, dominates the field of air microbiology; the leading institutions are Colorado State University and Peking University, which have contributed 14 and 26 articles, respectively; and the top three journals are Applied and Environmental Microbiology (Appl. Environ. Microbiol.), Atmospheric Environment (Atmos. Environ.), and Science of the Total Environment (Sci. Total Environ.). The annual publication volume for the subject of airborne microorganisms shows an increasing trend during the study period, peaking in 2019 with 49 articles (Fig. 6), and the number of citations has likewise steadily grown. Thus, we anticipate that interest in this topic will continue to rise over the next few years.

\subsection{Limitations}

This study has several shortcomings. First of all, we chose the Web of Science Core Collection as our sole data source, thereby excluding articles listed in other databases. Second, as the study period was 2011-2020, the publications for this year (2020) are incomplete. Third, our analysis uses the number of citations as a key indicator, but this number gradually increases as more articles are published. These issues are difficult to avoid in bibliometrics; nevertheless, they warrant better solutions in the future. Overall, our bibliometric analysis establishes the recent research hotspots and topic trends in air microbiology, thereby offering potential clues for related investigations.

\section{REFERENCES}

Adjorlolo, S., Egbenya, D.L. (2020). A twin disaster: Addressing the COVID-19 pandemic and a cerebrospinal meningitis outbreak simultaneously in a low-resource country. Global Health Action. 13, 1795963. https://doi.org/10.1080/16549716.2020.1795963

Alhazzani, W., Moller, M.H., Arabi, Y.M., Loeb, M., Gong, M.N., Fan, E., Oczkowski, S., Levy, M.M., 
Derde, L., Dzierba, A., Du, B., Aboodi, M., Wunsch, H., Cecconi, M., Koh, Y., Chertow, D.S., Maitland, K., Alshamsi, F., Belley-Cote, E., ... Rhodes, A. (2020). Surviving Sepsis Campaign: Guidelines on the management of critically ill adults with Coronavirus Disease 2019 (COVID19). Intensive Care Med. 46, 854-887. https://doi.org/10.1007/s00134-020-06022-5

Berman, J.D., Ebisu, K. (2020). Changes in U.S. air pollution during the COVID-19 pandemic. Sci. Total Environ. 739: 139864. https://doi.org/10.1016/j.scitotenv.2020.139864

Bowers, R.M., McLetchie, S., Knight, R., Fierer, N. (2011). Spatial variability in airborne bacterial communities across land-use types and their relationship to the bacterial communities of potential source environments. ISME J. 5, 601-612. https://doi.org/10.1038/ismej.2010.167

Brągoszewska, E., Biedroń, I., Hryb, W. (2019). Air quality and potential health risk impacts of exposure to bacterial aerosol in a waste sorting plant located in the Mountain region of Southern Poland, around which there are numerous rural areas. Atmosphere 10, 360. https://doi.org/10.3390/atmos10070360

Brodie, E.L., DeSantis, T.Z., Parker, J.P.M., Zubietta, I.X., Piceno, Y.M., Andersen, G.L. (2007). Urban aerosols harbor diverse and dynamic bacterial populations. Proc. Natl. Acad. Sci. U.S.A. 104, 299-304. https://doi.org/10.1073/pnas.0608255104

Cao, C., Jiang, W., Wang, B., Fang, J., Lang, J., Tian, G., Jiang, J., Zhu, T.F. (2014). Inhalable microorganisms in Beijing's $\mathrm{PM}_{2.5}$ and $\mathrm{PM}_{10}$ pollutants during a severe smog event. Environ. Sci. Technol. 48, 1499-1507. https://doi.org/10.1021/es4048472

Crook, B., Robertson, J.F., Travers Glass, S.A., Botheroyd, E.M., Lacey, J., Topping, M.D. (1991). Airborne dust, ammonia, microorganisms, and antigens in pig confinement houses and the respiratory health of exposed farm workers. Am. Ind. Hyg. Assoc. J. 52, 271-279. https://doi.org/10.1080/15298669191364721

del Rio, C., Malani, P.N. (2020). COVID-19-New insights on a rapidly changing epidemic. JAMA 323, 1339-1340. https://doi.org/10.1001/jama.2020.3072

Després, V., Huffman, J.A., Burrows, S.M., Hoose, C., Safatov, A., Buryak, G., Fröhlich-Nowoisky, J., Elbert, W., Andreae, M., Pöschl, U., Jaenicke, R. (2012). Primary biological aerosol particles in the atmosphere: A review. Tellus B 64, 15598. https://doi.org/10.3402/tellusb.v64i0.15598

Duan, L., Shao, X., Wang, Y., Huang, Y., Miao, J., Yang, X., Zhu, G. (2020). An investigation of mental health status of children and adolescents in china during the outbreak of COVID-19. J. Affective Disord. 275, 112-118. https://doi.org/10.1016/j.jad.2020.06.029

Fahimnia, B., Sarkis, J., Davarzani, H. (2015). Green supply chain management: A review and bibliometric analysis. Int. J. Prod. Econ. 162, 101-114. https://doi.org/10.1016/j.ijpe.2015.01.003

Fan, C., Li, Y., Liu, P., Mu, F., Xie, Z., Lu, R., Qi, Y., Wang, B., Jin, C. (2019). Characteristics of airborne opportunistic pathogenic bacteria during autumn and winter in Xi'an, China. Sci. Total Environ. 672, 834-845. https://doi.org/10.1016/j.scitotenv.2019.03.412

Fang, J., Dong, Q., Shen, W., Liu, X., Dou, N., Xian, L., Chen, H. (2020). Variation in near-surface airborne bacterial communities among five forest types. Forests 11,561 . https://doi.org/10.33 90/f11050561

Fröehlich-Nowoisky, J., Kampf, C.J., Weber, B., Huffman, J.A., Pöehlker, C., Andreae, M.O., LangYona, N., Burrows, S.M., Gunthe, S.S., Elbert, W., Su, H., Hoor, P., Thines, E., Hoffmann, T., Després, V.R., Pöschl, U. (2016). Bioaerosols in the Earth system: Climate, health, and ecosystem interactions. Atmo. Res. 182, 346-376. https://doi.org/10.1016/j.atmosres.2016.07.018

Gribble, K., Marinelli, K.A., Tomori, C., Gross, M.S. (2020). Implications of the COVID-19 pandemic response for breastfeeding, maternal caregiving capacity and infant mental health. J. Hum. Lact. 36, 591-603. https://doi.org/10.1177/0890334420949514

Iqbal, M.M., Abid, I., Hussain, S., Shahzad, N., Waqas, M.S., Iqbal, M.J. (2020). The effects of regional climatic condition on the spread of COVID-19 at global scale. Sci. Total Environ. 739, 140101-140101. https://doi.org/10.1016/j.scitotenv.2020.140101

Juliao-Baños, F. (2020). Manejo de pacientes con enfermedad inflamatoria intestinal durante la pandemia de COVID-19. Rev. Colomb. Gastroenterol. 35, 37-44. https://doi.org/10.22516/250 07440.537

Jung, T., Perez-Sierra, A., Duran, A., Jung, M. H., Balci, Y., Scanu, B. (2018). Canker and decline diseases caused by soil- and airborne Phytophthora species in forests and woodlands. Persoonia 40, 182-220. https://doi.org/10.3767/persoonia.2018.40.08

Kim, K.H., Kabir, E., Jahan, S.A. (2018). Airborne bioaerosols and their impact on human health. J. 
Environ. Sci. 67, 23-35. https://doi.org/10.1016/j.jes.2017.08.027

Lang-Yona, N., Ozturk, F., Gat, D., Akturk, M., Dikmen, E., Zarmpas, P., Tsagkaraki, M., Mihalopoulos, N., Birgül, A., Kurt-Karakuş, P.B., Rudich, Y. (2020). Links between airborne microbiome, meteorology, and chemical composition in northwestern Turkey. Sci. Total Environ. 725, 138227. https://doi.org/10.1016/j.scitotenv.2020.138227

León-Gómez, J., Gómez Aldana, A.J., Tapias Mantilla, M.L. (2020). Implicaciones hepáticas en la pandemia por COVID-19. Rev. Colomb. Gastroenterol. 35, 30-36. https://doi.org/10.22516/25 007440.535

Leung, W.W.F., Sun, Q. (2020). Electrostatic charged nanofiber filter for filtering airborne novel coronavirus (COVID-19) and nano-aerosols. Sep. Purif. Technol. 250, 116886. https://doi.org/1 $0.1016 / j$.seppur.2020.116886

Liu, J., Ma, W. (2010). Characteristics of airborne microorganism pollution in pig house. J. Anhui Agric. Sci. 28, 15665-15667. http://nsits.yingxiaoli.com/download/feiqiwu-wenxian/kongqikel iwu/52.pdf

Lozano, S., Calzada-Infante, L., Adenso-Díaz, B., García, S. (2019). Complex network analysis of keywords co-occurrence in the recent efficiency analysis literature. Scientometrics 120, 609629. https://doi.org/10.1007/s11192-019-03132-w

Parat, S., Perdrix, A., Baconnier, P. (1999). Relationships between air conditioning, airborne microorganisms and health. Bull. Acad. Natl. Med. 183, 327-342.

Rao, Y., Li, H., Chen, M., Huang, K., Chen, J., Xu, J., Zhuang, G. (2020). Community structure and influencing factors of airborne microbial aerosols over three Chinese cities with contrasting social-economic levels. Atmosphere 11, 317. https://doi.org/10.3390/atmos11040317

Romano, S., Di Salvo, M., Rispoli, G., Alifano, P., Perrone, M.R., Tala, A. (2019). Airborne bacteria in the Central Mediterranean: Structure and role of meteorology and air mass transport. Sci. Total Environ. 697, 134020. https://doi.org/10.1016/j.scitotenv.2019.134020

Romano, S., Becagli, S., Lucarelli, F., Rispoli, G., Perrone, M.R. (2020). Airborne bacteria structure and chemical composition relationships in winter and spring $\mathrm{PM}_{10}$ samples over southeastern Italy. Sci. Total Environ. 730, 138899. https://doi.org/10.1016/j.scitotenv.2020.138899

Stadnytskyi, V., Bax, C.E., Bax, A., Anfinrud, P. (2020). The airborne lifetime of small speech droplets and their potential importance in SARS-CoV-2 transmission. Proc. Natl. Acad. Sci. U.S.A. 117, 11875-11877. https://doi.org/10.1073/pnas.2006874117

Synnestvedt, M.B., Chen, C., Holmes, J.H. (2005). CiteSpace II: Visualization and knowledge discovery in bibliographic databases. AMIA Annu. Symp. Proc. 2005, 7254-728.

Tignat-Perrier, R., Dommergue, A., Thollot, A., Keuschnig, C., Magand, O., Vogel, T.M., Larose, C. (2019). Global airborne microbial communities controlled by surrounding landscapes and wind conditions. Sci. Rep. 9, 14441. https://doi.org/10.1038/s41598-019-51073-4

Tignat-Perrier, R., Dommergue, A., Thollot, A., Magand, O., Amato, P., Joly, M., Sellegri, K., Vogel, T.M., Larose, C. (2020). Seasonal shift in airborne microbial communities. Sci. Total Environ. 716, 137129. https://doi.org/10.1016/j.scitotenv.2020.137129

Van Rheenen, T.E., Meyer, D., Neill, E., Phillipou, A., Tan, E.J., Toh, W.L., Rossell, S.L. (2020). Mental health status of individuals with a mood-disorder during the COVID-19 pandemic in Australia: Initial results from the COLLATE project. J. Affective Disord. 275: 69-77. https://doi.org/10.1016/j.jad.2020.06.037

Wan, G.H., Lu, S.C., Tsai, Y.H. (2004). Polymerase chain reaction used for the detection of airborne Mycobacterium tuberculosis in health care settings. Am. J. Infect. Control 32, 17-22. https://doi.org/10.1016/s0196-6553(03)00090-7

Yang, K., Li, L., Wang, Y., Xue, S., Han, Y., Liu, J. (2019). Airborne bacteria in a wastewater treatment plant: Emission characterization, source analysis and health risk assessment. Water Res. 149, 596-606. https://doi.org/10.1016/j.watres.2018.11.027

Yoo, K., Lee, T.K., Choi, E.J., Yang, J., Shukla, S.K., Hwang, S.I., Park, J. (2017). Molecular approaches for the detection and monitoring of microbial communities in bioaerosols: A review. J. Environ. Sci. 51, 234-247. https://doi.org/10.1016/j.jes.2016.07.002

Zhao, Y., Aarnink, A.J.A., De Jong, M.C.M., Groot Koerkamp, P.W.G. (2014). Airborne microorganisms from livestock production systems and their relation to dust. Crit. Rev. Environ. Sci. Technol. 44, 1071-1128. https://doi.org/10.1080/10643389.2012.746064 